\title{
Building Circular Economy: a Case Study Designed and Built Following a BIM-Based Life Cycle Assessment Approach
}

\author{
Mauro Manca ${ }^{1}$, Zuzana Prochazkova ${ }^{1}$, Umberto Berardi ${ }^{2}$, Licinio Alfaro ${ }^{3}$ and Felipe \\ Pich-Aguilera ${ }^{1}$
}

${ }^{1}$ CEIM, Universitat Internacional de Catalunya, Carrer de la Immaculada, 22,08017 Barcelona, Spain m.manca@picharchitects.com

${ }^{2}$ Ryerson University Toronto, 350 Victoria St, Toronto, ON M5B 2K3, Canada, uberardi@ryerson.ca

${ }^{3}$ ITEC, Carrer de Wellington, 19, 08018 Barcelona, Spain, lalfaro@itec.cat

\begin{abstract}
The awareness of the environmental impact of buildings during their entire whole life cycle has seen a growing interest in recent years. In fact, as buildings become more energy-efficient, life cycle impacts become increasingly important. Investors in the building sector are becoming aware of the direct and indirect benefits of a design process that enables the control of the impact of the building, ensuring the higher quality, intrinsic value of materials under a circular economy point of view. The durability is, together with reusability and recyclability, one of the main characteristics of construction materials. In this framework, the purpose of this paper is to describe a BIM-based approach to life cycle assessment (LCA) from the initial stages of the design of the Socrates Building in Viladecans. For this scope, a digital model in the TCQi GMA software was created to assist in the evaluation, optimization, and comparison of different design and construction alternatives. An integrated project delivery contract was adopted. These aspects altogether showed the potential of increasing the real estate value and the profitability of the building. This paper discusses problems that emerged during the digital project management, assessing criticalities and opportunities.
\end{abstract}

Keywords: LCA, Circular Economy, Prefabricated Construction.

\section{Introduction}

The Socrates Building is a mixed-use building that allows to explore the challenges of a new model of design and construction based on the circular economy. The building is located in Viladecans Business Park, close to Barcelona, a new business development area dedicated to emerging companies and new business models. The basis of achieving a building of circular economy was to ensure that the building could adapt to a wide range of uses that span from offices to tertiary. This goal was pursued with the following main directives: maximum spatial flexibility, structural durability, material disassembling and traceability and comfortable and healthy occupied spaces, followed an approach often only fully presented in theory (Berardi, 2015).

An industrialized and dry construction systemic approach was chosen as the best option to respond effectively to life cycle strategies and to reduce the negative impact of the operational phase and deconstruction phase. Construction materials were chosen according to their level of traceability, fostering the use of Cradle to Cradle materials, and the commitment of the contractor to select products with a material passport or Environmental Declaration of Product 
(EPD). The decision-making during the design process was supported with a Life Cycle Assessment (LCA) developed with a digital BIM model and implemented with environmental impact data of the BEDEC database.

An important part of the process was dedicated to conceiving a building with an increased value during its operational phase, which is usually the highest impact in the life cycle (Asdrubali et al., 2013). Therefore spaces were designed utilizing energy simulations to ensure optimal lighting and thermal comfort (Bernstein, 2011), and to give a direct benefit to energy conservation and a subsequent reduction in operating costs.

Another keystone in the design was to support direct access to nature and open spaces with vegetation, natural ventilation and direct access to daylight and views. Each floor plan possesses open space equipped with vegetation, irrigated with recovered rainwater. The LEED v.4 certification protocol was adopted to better structure all of the aspects related to sustainability, this decision was taken in accordance with an analysis of the office buildings market in Barcelona where the majority of buildings with environmental certifications have a higher real estate value and higher rental potential (Eje Prime, 2018). A final practical aspect of the design and construction phase was the implementation of an integrated delivery process (IDP) that aligned every stakeholder towards the common goal of conceiving a circular economy building.
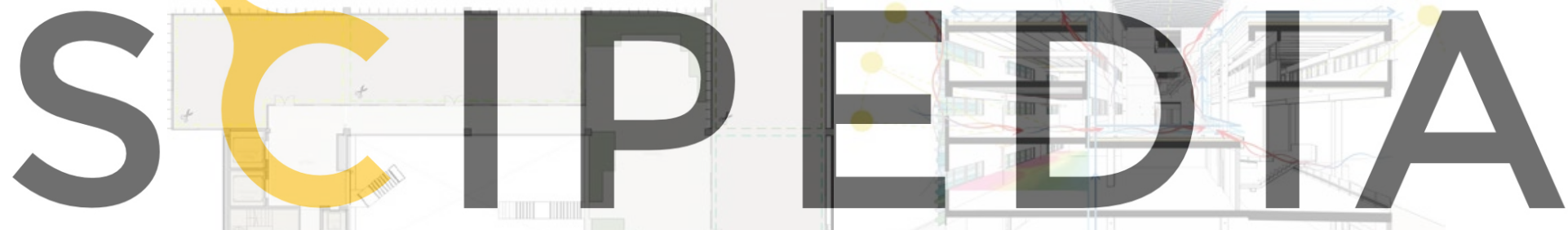

Register for free at https//www.scipedia.com to download the version without the watermark $+$

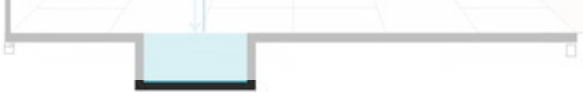

Figure 1. Type floor plan with interior subdivision schemes (left) and section (right) of the Socrates building.

\section{Main Building Characteristics}

The building comprises four levels: the first two stories are accessible to automated vehicles whereas the upper floors are designed according to office criteria. Open common spaces are provided on each floorplan and located to the core of the building, also serving as connection and circulation zones. The rooftop hosts a common terrace partially covered with a green substrate and an area dedicated to HVAC plant equipment and PV.

\subsection{Construction Elements}

Particular attention was dedicated to structural design as it is considered to be one of the most influential components of the building, remaining practically unchanged through the whole life cycle affecting its duration and the resulting building economy (Manganelli, 2014). The 
building is designed to be fully industrialized and assembled onsite. This process guarantees a more effective construction process by reducing the construction time schedule, minimizing onsite waste production, facilitating the traceability of each material and its revalorization at the end of the lifecycle.

The structure is constructed from a prefabricated concrete frame composed of $0,60 \mathrm{~m} \times 0,80$ $\mathrm{m}$ pillars that span the full height of the building as a single element without vertical interruption in addition to horizontal beams with a section of $60 \times 80 \mathrm{~cm}$ that connects to the vertical structure. Pillars are distributed across a $10 \times 10$-meter grid, with a $100 \mathrm{~m}^{2}$ free areas that guarantee the highest spatial flexibility for any tertiary and light industrial use. Prefabricated hollow-core slabs complete the horizontal enclosure and give structural stability to the frame.
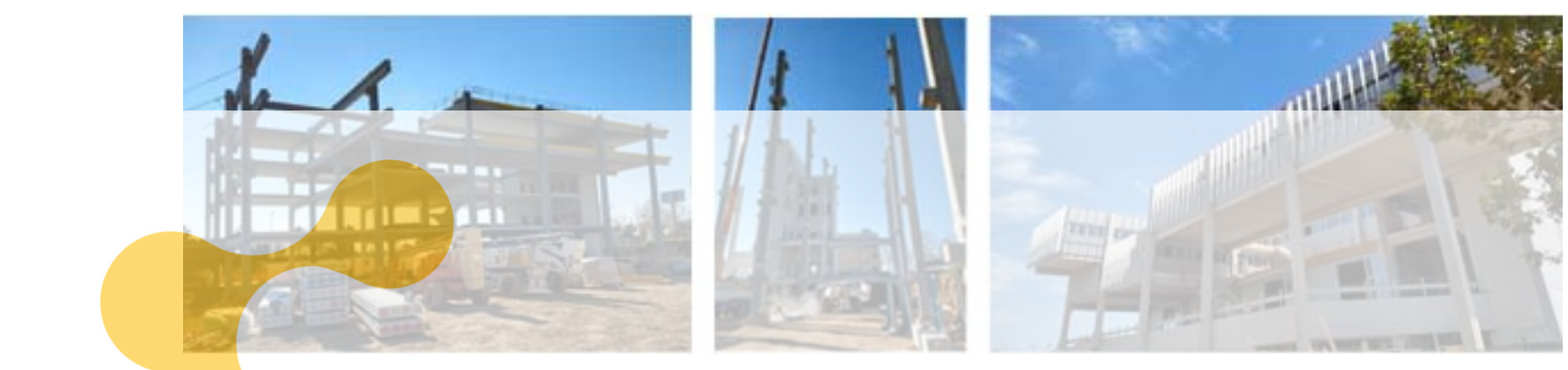

Figure 2. Prefabricated structure during the construction phase of the Socrates building.
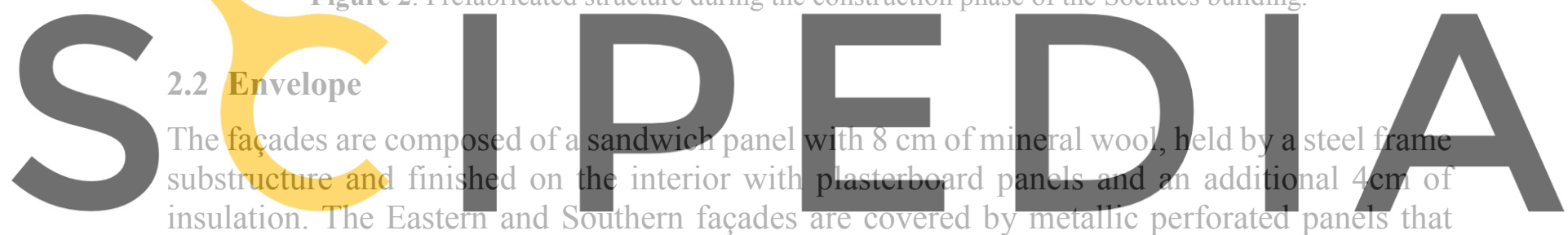

leave sufficient space for natural ventilation and HVAC ducts and piping.

Register for free at https//www.scipedia.com to download the version without the watermark
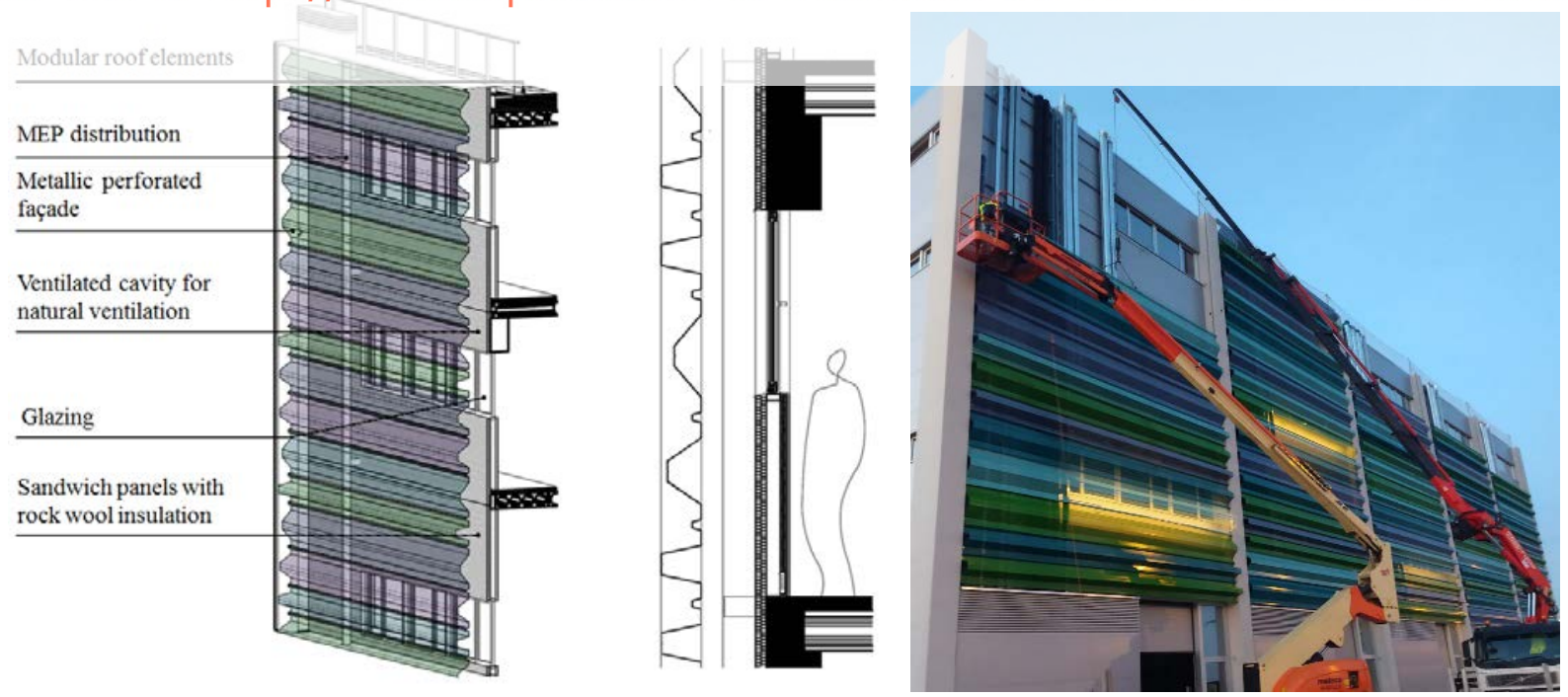

Figure 3. 3D of the façade (left), façade section (center) and construction phase (right) of the Socrates building. 
All the horizontal enclosures in contact with occupied spaces present a waterproof layer covered by $10 \mathrm{~cm}$ of XPS thermal insulation. The roof garden consists of an industrialized green roof, modular elements that include the irrigation system. The remainder of the roof and terraces are covered with concrete floor tiles. Interior spaces are left without any additional finishing.

\subsection{Mechanical, Electrical, and Plumbing}

The HVAC system, linked with a geothermal heat pump of $303 \mathrm{~kW}$, acts as the primary system and covers $80 \%$ of the demand for heating and cooling power. A water to air heat pump of $316 \mathrm{~kW}$ supports the system during peak demand. The installation of $45 \mathrm{kWp}$ of PV panels is estimated to produce $60.000 \mathrm{kWh}$, covering $38 \%$ of the expected energy consumption. The distribution systems run along the façade, connecting to the ventilation system of each interior space. This configuration was chosen to facilitate ease of maintenance and to improve internal spatial flexibility, offering multiple options of connection to services externally with no implication to the interior spaces.

\section{Methodology}

\subsection{Application of an Integrated Process for the Building Life Cycle}

Energy simulations with Energy plus were performed to optimize the building envelope for the thermal comfort. Daylight analysis determined the volumetric and spatial definition of the building, assisting with the interior design considerations that according to a different range of options in favor of maximum spatial flexibility. At the same time, an LCA vas performed w the digital BIM model of the architectural proposal, then Integrated with a personalized database of construction products, based on BEDEC construction products with technical details, c

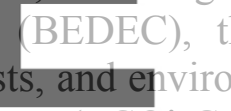

process took place within the TCQi-GMA software (TCQi-GMA).

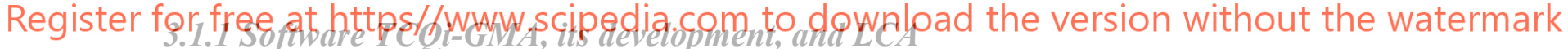

The TCQi-GMA (TCQi) is used for life cycle assessment and other applications of construction projects developed by IteC. It is based on TCQ2000 (TCQ), a software developer for the construction sector, formed by a set of applications to support the activities of the edition, contracting, planning and control of projects and construction sites. It includes indicators on time, cost, quality, security, waste generation and embodied energy. A specific methodology is used to calculate the environmental data, similar to the one used in eco-labels type III. The categorization of products and services for the construction sector, as defined by the European standard EN 15804 (EN 15804), is applied. Materials durability, joints disassemblability, and material positioning within a layer play a vital role in the process.

\subsubsection{Application of the process in the Socrates building}

The inputs for the LCA of the Socrates building were:

- The budget of the project in Excel, created by the construction contractor and;

- A set of 3D models converted to .IFC file format from various 3D modeling software. The 3D models provided consisted of b1) a foundations model, b2) a structural model, 
created in Tecla by the provider of prefabricated structure b3) an HVAC model provided by the installation engineer, and of b4) an architectural model produced by the architects.

Eight chapters of LCA were defined for the project: demolition \& groundworks, foundations, structure, building services, civil works, rainwater storage system, private urbanization, elevators, and extra modifications.

Each chapter was assigned a construction system as defined in the BEDEC database and given a specific code associated with detailed information about its construction process and the cost. During the next phase, the IFC models are associated with the TCQ2000 structure. Each of the four 3D models is integrated within the software. The different components were then manually selected and associated with the corresponding chapters of the created structure. The unit to import the BOQ is selected, and the BOQ is imported to the TCQ2000 structure. Some of the elements presented in the original budget file did not have representation in the $3 \mathrm{D}$ model, therefore the BOQ data comes from various sources: a) from the 3D model; b) from the Excel file, and c) calculated manually when incomplete in both inputs. Once the digital model has been defined, the LCA is performed, using the TCQi-GMA software. When uploading the structure from the TCQ2000 to TCQi, the software analyses the provided data and evaluates how complete the environmental data is, as defined by the structure.

In the Socrates Building, the information related to the waste generation is $100 \%$ complete, while the information referring to Energy and CO2 generation is missing in 9.09\% (Gris and Alfaro, 2019). In order to complete the information, the incomplete chapters can be adapted, assimilated or completect supplier, such as volum CO2 emission. Once construction phase is dete data about the use phase,
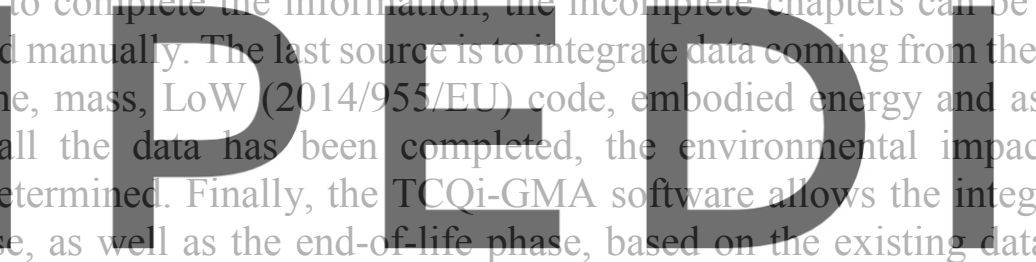

well as maintenance manuals, when specific information is not available.

Register for free at https//www.scipedia.com to download the version without the watermark 4 Results

As a result of the implementation of energy simulation during the design process, the maximum depth of the volumes on the $2^{\text {nd }}$ and $3^{\text {rd }}$ floors was set to 10 meters, ensuring a 10 -meter patio to the core. This strategically allowed openings towards an interior zone with better acoustic conditions. This choice guaranteed at least $2 \%$ of Daylight Factor (DF) across $75 \%$ of working areas and an efficient level of natural ventilation. The overall energy consumption of the proposal is reduced by $40 \%$ compared to the corresponding baseline model designed according to ASHRAE 90.1.

Concerning the LCA, detailed data related to the product, construction, use, and end of life phases have been studied. 8 chapters of the construction work divided into earth movement, foundations, structure, civil works, rainwater storage, private urbanization, elevators, and extra modifications. The BEDEC database was used for product and construction phases. Relationship with use and end of life future phases has been created, but not completed due to lack of information. At the current stage, the total LCA information for the foundations and structure phases has been created (Fig. 4). 
The overall results considering the product and construction phase show the largest impact during the product phase (2.453.247 $\mathrm{kg} \mathrm{CO}_{2}$ eq). The construction phase impact is low (448.129 $\mathrm{kg} \mathrm{CO} 2$ eq). In the product phase the impact is distributed mostly between the foundations (542.000 $\mathrm{kg} \mathrm{CO}_{2}$ eq,), structure (846.885 $\mathrm{kg} \mathrm{CO}_{2}$ eq,) and civil works (883.000 $\mathrm{kg} \mathrm{CO}_{2}$ eq,). The civil works contain all the non-load bearing elements of the building envelope, interior partitions, and finishing. The rest of the construction categories in total count less than 181.000 $\mathrm{kg} \mathrm{CO}_{2}$ eq. The prefabricated concrete structure causes the largest impact during the construction phase, with $409.028 \mathrm{~kg} \mathrm{CO}_{2}$ eq compared to the second-largest impact by the earth moving with $25.000 \mathrm{~kg} \mathrm{CO}_{2}$ eq.

To achieve the total LCA, relations are being created between the different work items and the future items of works during the use phase and end of life phase. This process requires an important time dedication because each item that defines the construction work needs several works items to calculate the future impact. However, once the relationship has been created, it can be applied or adapted for future use in another project, becoming part of the company's own knowledge and future business. Unlike other LCA software that performs generic calculations in different scenarios, the methodology used in this paper identifies each material and associated construction processes, creating relationships reflecting the real construction work in detail, in order to conduct in-depth analysis, introduce the disassembly capacity or the material passport identification.
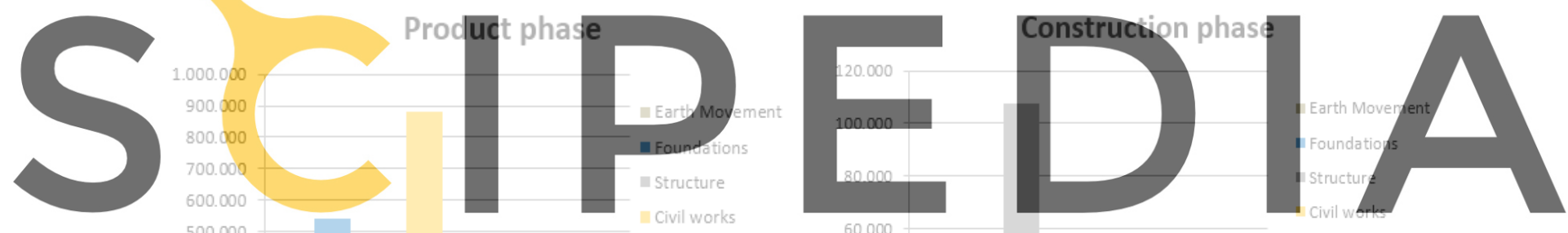

500.000 60.000

Register forbofree at https//www.scipedia.comizto
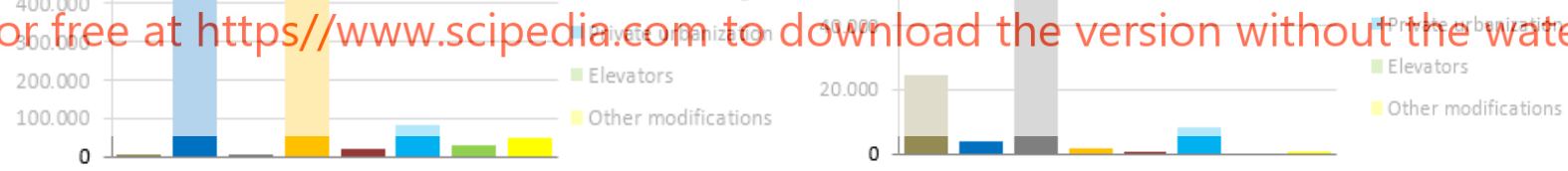

Figure 4 Global Warming potential in $\mathrm{kg} \mathrm{CO}_{2}$ eq: Product phase (left), and Construction phase (right).

Finally, in the Socrates Building, $88 \%$ of the construction materials have been identified and defined for its recyclability at the end of life, amounting to 7.800 tons. Moreover, $84 \%$, accounted for its weight has a Cradle-2-Cradle certificate. The design and construction process has guaranteed a minimum waste production calculated for 25 tons of waste material, including excavation consisting of only $4 \mathrm{~kg}$ of waste per square meter of construction: $100 \%$ of this waste can be traced by a waste management protocol and $99,3 \%$ is re-valorized.

\section{Discussion and Conclusions}

The new Socrates Building close to Barcelona was designed to be an example of the integration of circular economy in the construction sector. This experience has outlined some criticalities and opportunities, as discussed here. 
As a first consideration, it is worth highlighting the importance of an integrative process during design and construction. The integration of all the stakeholders with an IDP was beneficial for technical and construction decisions, giving the opportunity to incorporate synergy to the whole value chain, allowing constant control on cost and quality. However, the IDP contract was introduced just before the construction works, causing initial maladjustment that produced an increase in technical costs. This could have been avoided by including this strategy from the start of the design phase.

As a general consideration of the circular economy, the Socrates Building is presented as a dynamic system of parts and functions attached to specific uses that can vary during its life cycle. The concept of the circular economy includes not only the life cycle of construction material but also the operational phase and the increased value derived from spatial flexibility, the health and comfort of occupants that can give greater performance, energy and economic savings during use and maintenance. This aspect is crucial for the generation of a different business model for tertiary buildings, moving the focus from only the environmental impact to include the quality of the service and the sub-sequential impact on occupant satisfaction and employee retention. In fact, employee cost is usually estimated to reach up to $90 \%$ of building cost (Attema et al., 2018) and every improvement under this aspect can have much higher savings if properly quantified.

Concerning the lifecycle analysis, data availability is an important issue in the construction sector. In the Socrates project it was enhanced, as most of the products were Cradle-2-Cradle certified or had the

barriers in applying consolidated data, es systems in the use replacement, and refurbishn methodology. In ordar
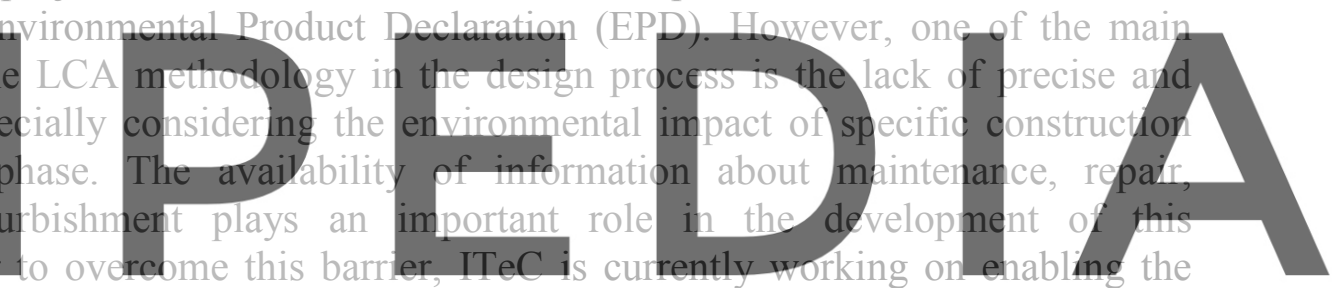

BEDEC users to create their own online database of construction systems, using the elements

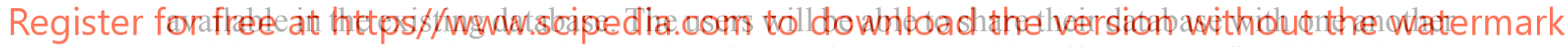
and integrate them into their TCQi Software for LCA. This offers more flexibility in the exchange of information and in the acquisition of information for specifications, planning and construction tracking. Furthermore, with the increasing implementation of big data analysis and artificial intelligence, the statistical data will allow us to determine the most appropriate systems and installation methods for any geographical orientation or location, as well as being able to determine product needs or the capacity for growth based on existing resources in a specific area.

In order to consider the environmental impact of the construction beyond the system boundary, the reuse, recovery and recycling potential has to be considered in the life cycle assessment. Another issue identified in the process was the interoperability of software and the diverse needs of the LCA methodology on how to create the 3D model of the building.

Finally, the Socrates Building can be considered as one of the first real case studies for the integration of circular economy in the building sector. The next step required for a business model of the circular economy will be to consider each component of the life cycle in terms of intrinsic economic value in the real estate market so that buildings will increase its value beyond standard indicators and so enhancing the interest in sustainable buildings. 


\section{ORCID}

Umberto Berardi: https://orcid.org/0000-0002-0508-6195

\section{References}

ANSI/ASHRAE/IES Standard 90.1-(2010). Energy Standard for Buildings Except Low-Rise Residential Buildings

Asdrubali F., Baldassarri C., Fthenakis V. (2013). Life cycle analysis in the construction sector: Guiding the optimization of conventional Italian buildings, Energy and Buildings 64, 73-89

Attema, J.E., Fowell, S.J., Macko, M.J. and Neilson, W.C. (2018). The Financial Case For High PerformanceBuildings. San Francisco: Stok, LLC.

BEDEC. Retrieved from https://itec.es/servicios/bedec/

Berardi U. (2015). Sustainability assessment of buildings, communities and cities, chapter in the book, Assessing and Measuring Environmental Impact and Sustainability, ed. Jiri Klemeš, Elsevier.

Berardi U. (2017). A cross country comparison of building energy consumption and their trends, Resource Conservation and Recycling, 123, 230-241.

Bernstein H. M. (2011). Outlook 2011 Executive Conference, McGraw-Hill Construction Reports 2011 EjePrimeEdiciones, SLU (2018). Retrieved from :https://www.ejeprime.com/oficinas/las-oficinas-en-buscadel-sello-el-14-de-los-edificios-de-madrid-y-barcelona-son-sostenibles.html

CEN/TC 350 Sustainability of construction works

EN 15804:2012(2014). Sustainability of construction works - Environmental product declarations - Core rules for the product category of construction products

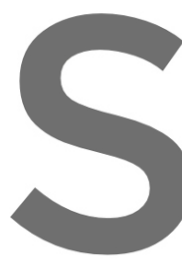

EN 15978: (2011). Sustainability buildings: Calculation method

Finkbeiner M., Schau Sustainability $2(10)$,

Gris R., Alfaro L. (2019). An thesis, Universitat Politècnica de $\mathrm{C}$
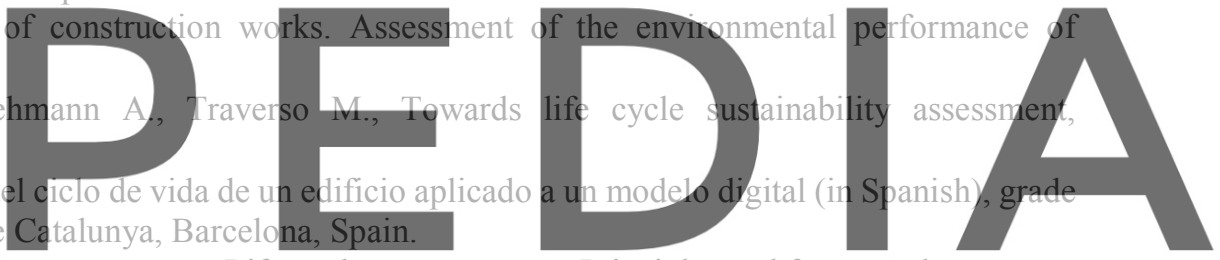

ISO 14040: (2006). Environmental management — Life cycle assessment — Principles and framework

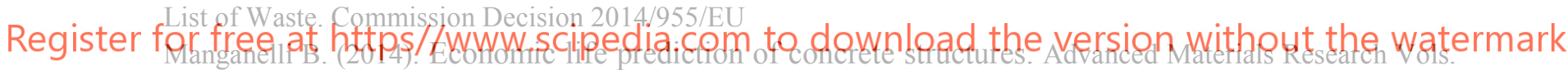
919-921 (2014) pp 1447-1450

Socrates Building website, Retrieved from https://www.edificio-socrates.com

TCQ/ TCQi. Retrieved from https://itec.es/programas/tcq/

TCQi-GMA. Gestión del modelo ambiental. Retrieved from https://itec.es/programas/tcqi/gestion-ambiental/ 